Elsevier required licence: (C) $<2016>$. This manuscript version is made available under the CC-BY-NC-ND 4.0 license http://creativecommons.org/licenses/by-nc-nd/4.0/ 


\title{
HOLIDAY BODIES: YOUNG WOMEN AND THEIR APPEARANCE
}

\begin{abstract}
A holiday is an embodied experience yet little is known about how one's body image or physical appearance affects the experience. The study employed Memory-work to examine how young, Australian women felt about their physical appearance on holiday. The findings indicated that the women experienced their appearance through surveillance, social comparison and feedback. While most memories reflected reinforcement rather than resistance to the dominant discourse on women's appearance, experiences were contingent on the destination, type of holiday and the other people present. Viewing the body, not as static but, as "becoming" offers hope for transgression. The study contributes to the embodiment literature in examining the lived experiences of appearance in a holiday environment which is often gendered and sexualised.
\end{abstract}

Keywords: Young women; physical appearance; body image; holiday; embodiment

\section{INTRODUCTION}

Body image is a concerning social topic of discussion and research resulting in a well-developed field of knowledge in the behavioural and social sciences. The focus of attention has been Western culture's fixation on a thin-body ideal for women and the potential normative body dissatisfaction females experience when they perceive they do not meet this ideal (Polivy \& Herman, 2002). Body image can have a powerful effect on our quality of life with poor body image related to declining self-esteem, negative mood, mood disturbances and unhealthy weight loss practices (Clay, Vignoles \& Dittmar, 2005; Pinhas, Toner, Ali, Garfinkel \& Stuckless, 1999). In Western societies, body dissatisfaction is so prevalent it has been referred to as "normative discontent" (Rodin, Silberstein \& Striegel-Moore, 1984). While body image is important to men, especially in regards to muscularity (Olivardia, 2002), women are considered to be particularly susceptible to societal views on physical appearance and attractiveness. Physical appearance and body image can relate to all parts and aspects of the body but Western societal concern primarily relates to the female thin-body ideal. For many women, identity, success, sexuality and value stem from their appearance. While body image concerns all age groups, it is especially important to young people (Mission Australia, 2013). To understand body image and its lived experience in 
Western industrialised countries requires an appreciation of neoliberal discourses which emphasise free choice, self-responsibility, lifestyle and consumption.

The insidiousness of body image concerns in everyday life raises the question: are there some social spaces outside the everyday in which women can contest these norms? One possibility of a counter site, or heterotopia (Foucault, 1984), is a leisure or tourism space. Certainly, there are some leisure spaces and activities where women have transgressed the constraining gendered body prescriptions and, in so doing, gained a sense of empowerment (see Wearing, 1998). Specific types of leisure may also provide opportunities for women to learn about their bodies and gain an expanded sense of their body's potential (Yarnal, Hutchison \& Chow, 2006). On the other hand, leisure researchers have found that body image and feelings about appearance can constrain leisure activities through reduced participation or reduced enjoyment in the activity (Frederick \& Shaw, 1995; James, 2000; Liechty, Freeman \& Zabriskie, 2006). As a form of leisure, the holiday is often seen as a liminal time and space, a point of difference from the everyday, a time of fantasy and perfection, of escape from the personal and societal pressures at home. As the writer, Amy Tan, in Saving Fish from Drowning exhorts, "Seek and you shall find your illusions through the magic of tourism" (2005, p.147). At the same time, others argue that "everyday life and tourism are not separate realms of practice" (Hannam \& Knox, 2010, p. 103). Crouch and Desforges in referring to tourism as performance, explain the tension between tourism involving the reproduction of social habits and tourism as "“becoming', the possibility of making something different from only pre-figured and mundane protocols" (2004, p. 10). The question remains whether the holiday is a time and space differentiated from the everyday which permits resistance of appearance prescriptions or whether these prescriptions persist for women on holiday. It is possible that for an important event like a holiday, body image can become even more important for women. Certainly, research on special events, such as weddings (Neighbors \& Sobal, 2008; Prichard \& Tiggemann, 2011), has found that body shape and weight are important for many brides and bridesmaids in achieving wedding perfection. They want to look good and feel beautiful on this special occasion and in the wedding photos. As Prichard \& Tiggemann claimed: "their appearance on the day can be seen as critical to the day's success" (2011, p. 282). As with weddings, a holiday may also be a special event with a substantial emotional, social, temporal and financial investment. With such investment there may be pressure for the holiday to be as perfect as possible, including perfection of the body. Certainly, 
women's magazines and tourism media promote the "holiday (beach) body" as they do the "bridal body".

That tourism is an embodied experience is now well recognised (Crouch \& Desforges, 2003; Pritchard, Morgan, Ateljevic \& Harris, 2007; Small, 2007; Swain, 2004; Veijola \& Jokinen, 1994). The tourist experiences a holiday mentally as well as physically, neither is privileged over the other but rather is experienced as an integrative whole, fluid and temporal, "constantly in the making" (Weiss cited in Swain 2004, p. 104). A growing appreciation of the corporeal component of tourism has led a number of researchers to study the "the holiday body" through representations and associated discourses in the media. However, a notable gap in tourism studies is a consideration of how body image or the look/physical appearance of the body is experienced by tourists/holidaymakers, that is, how those involved understand and feel about the appearance of their body and how it contributes to overall holiday satisfaction. The present paper reports a study of young Australian women's experiences of their physical appearance when on holiday and examines whether the holiday is a time in which young women can escape the societal pressures of the $21^{\text {st }}$ century which prescribe normative body image or whether such prescriptions remain intact to affect the success of the holiday.

\section{YOUNG WOMEN'S BODY IMAGE/APPEARANCE ON HOLIDAY}

Criticism about the representation of women's bodies in the media focuses on the singular image of the ideal body. Analyses of tourism media: in-flight magazines (Small, Harris \& Wilson, 2008) and holiday brochures (Jordan, 1998; Pritchard, 2001) reveal that tourism promotional material reinforces this message with a significant amount of advertising centred on representations of attractive, young, white women and their objectification as sexual beings. In a study of the social messages in British women's lifestyle magazines directed at tourists' bodily preparation for a holiday, Jordan (2007) found there was a uniform beach-holiday body to which women should aspire: slim, toned, tanned and well-groomed. The message of the magazines is that one should work to achieve this body and "that without such a body women should not be happy to be unclothed in the public spaces of tourism" (p. 16). The image of the young, tanned, beautiful body, rather than inviting a woman to imagine herself as such, can, through undermining a woman's confidence, deter her from participation (Jordan, 1998). 
While representations are relevant for an understanding of body image/physical appearance, so too is a "non-representational" approach with an interest "in the subject and in what people themselves make of their lives" (Crouch, 2000, p. 63). Obrador-Pons (2003) refers to the centrality of the body in our engagement with the world. Women "perform" and "do" physical appearance. They diet, exercise, tan, apply makeup, style hair, exfoliate and clothe themselves. Yet, there has been limited investigation into women's lived experience of their physical appearance on holiday. Abramovici (2007), in her study of the behaviour of Italian women at the beach, highlights the body performance of tanning, arranging bikinis and parading for the gaze of others. Small's (2005) study of Australian women's and girls' memories of good and bad holiday experiences at different ages demonstrates the importance of physical appearance in the memories of holidays when women were young, around the age 20. The detailed memories of clothing worn (even 65 years after the event) suggested the importance of women's dress at this age and how women's image of how they looked affected their enjoyment of the holiday. The importance of appearance in women's holiday experience is supported by Berdevchesky, Gibson and Poria (2014). In a study of women's sexual roles on holiday, they found that while a holiday was a site for resistance to the dominant discourse of women's sexual passiveness and subordination through inversion of sexual roles, the dominant discourse on appearance persisted: "women's confidence to transgress sexual roles in tourism was reliant on their perceptions of their bodies as abiding by the beauty/femininity standards dictated by these same roles (2014, p. 11). In other words, "sexual confidence was contingent upon their self-perception as sexy/feminine/attractive, while their bodies had to be in the best shape for holidays" (2014, p.11)

Concern for the management, maintenance and appearance of the body has been referred to by Shilling (2003) as the "body project". Considering the body "unfinished" at birth, he explains: "In the affluent West, there is a tendency for the body to be seen as an entity which is in the process of becoming; a project which should be worked at and accomplished as part of an individual's self identity" (p. 4). In other words, "Bodies become malleable entities which can be shaped and honed by the vigilance and hard work of the owners" (p. 5). Shilling explains that one does not need to work full time at a complete transformation of the body but there is the potential for this to occur. The modern-day concern is that women, especially young women, can turn the body project into a full-time occupation with their focus on the "thin ideal". So while the body is "a text of culture", it is also "a practical, direct locus of social control" (Bordo, 1989, p. 13). As 
stated by Shilling (2003), the body is "a corporeal phenomenon which is not only affected by social systems, but which forms a basis for and shapes social relations" (p. 88). According to Foucault (1980), these social systems or "dominant discourses" render our bodies "docile" and "normalized", through bodily discipline and social and self-surveillance, whereby each individual exercises surveillance "over, and against himself" (Foucault 1980, p. 155). Through the process of gazing and being gazed upon we learn the standards of physical appearance and become the bearers of the discourse. However, we are also capable of resisting these discourses, (Foucault, 1980).

Feminist critique extends this thinking in relation to women's bodies. Objectification theory (Fredrickson \& Roberts, 1997) similarly proposes that from an early age women learn "objectified body consciousness" which involves "body surveillance" (seeing themselves as others see them), "internalisation of cultural standards" (in which the woman comes to see these standards as her choice) and "beliefs about appearance control" (in which the woman feels she is responsible for the way her body appears) (McKinley \& Hyde, 1996). McKinley explains the outcomes of internalisation:

internalization predisposes women to connect achievement of these standards with their sense of self-worth. Because the standards are narrow and difficult to achieve, women experience a sense of empowerment as they approximate them but more often shame when they do not. (2004, p. 57)

According to many feminists (see Jeffreys, 2005), the interiorised gaze is, an oppressive male gaze which should be resisted, while others argue that today's women have choices and that even conforming to the dominant image of the body is not necessarily oppressive. As Felski argues, there has been a distinct shift from a "rhetoric of victimization and oppression to an alternative language of empowerment and resistance" (2006, p. 280). This is possible if bodies are viewed "not as objects upon which culture writes meanings, but in terms of what a body can do" (Coffey 2013, p. 6). Applying Deleuzian concepts, Coffey (2013) discusses the "becoming of bodies", bodies as processes, events which are constituted and reconstituted "through their connections with other bodies and things" (2013, p. 6). As Coffey says, "This new, more positive approach to bodies as intensities exerting force (rather than femininity, for example, being seen as effect of 
patriarchal culture) moves beyond the binary, static opposition of feminine/masculine identities" (2013, p.13).

The limited tourism findings on the lived experience of the body, the body's 'becoming', prompted further investigation into how women experience their physical appearance in the social context of a tourist holiday. One might question whether this is a space which demands bodily perfection. Certainly, the holiday (especially the beach holiday) can be considered a sexualised space (Jordan \& Aitchison 2008). As noted by Richards, "The surveillant gaze may become even more crucial on holiday, as bare flesh is exposed to the view of strangers on the beach" (2002, p. 4). On the other hand, it may be seen as "a space over which the person has some control to be used for the person's own satisfaction" (Wearing, 1990, p. 44), where women can choose to comply with or resist normative behaviour, where ideologies can be negotiated. Davidson adds that because of the temporary nature of holidays, negotiation of normal rules is "not perceived to cause harm" (1996, p. 56).

The present study goes beyond a representational approach of the body to explore young, Australian women's understanding of their physical appearance in the sociocultural context of a holiday. It examines women's thoughts and feelings about their appearance and the salience of appearance to the success of a holiday or specific types of holiday, questioning whether the holiday is a site for the reinforcement or resistance of women's feminised (through physical appearance) identities. Since the focus of the body image literature relates to self-perceived physical appearance, both terms, "physical appearance" and "body image" are used in this paper when referring to the literature. However, since body image can also theoretically encompass perceptions of one's competency and strength, for the purposes of the empirical data collection, participants were specifically asked about their "physical appearance" since "the look" of the body was the focus of investigation.

\subsection{Study Methods}

The research method was Memory-work (Haug, 1987), a social constructionist feminist method which explores the social, shared meaning of life experiences. The underlying theory of Memorywork is that "subjectively significant events, events which are remembered, and the way they are subsequently constructed, play an important part in the construction of self" (Crawford, Kippax, Onyx, Gault \& Benton, 1992, p. 37). Since the theory considers that the self is socially 
constructed through reflection, memories are the data. Memory-work has grown in popularity with researchers from diverse disciplines and fields of study (see Small, 2004) seeking a research method that fits with a social constructionist, feminist paradigm. The focus of the present study was memories of recent holidays with specific reference to physical appearance. Since the method considers that one is an expert in one's own experiences, the barriers between the subject and the object of research are broken down. Memory-work stresses collective theorising. It is the inter-subjective nature of Memory-work, as opposed to a subjective or objective claim for the status of knowledge produced, which differentiates Memory-work from other research methods such as in-depth interview. Memory-work is also a feminist method in that it was developed for women with the aim of liberation. Through sharing experiences and interpretations with women similar to oneself, it is hoped that women can come to a new understanding of their experiences and how they have been constructed.

2.1.1 Memory-work Phases. There are three phases to the method. In Phase 1 (prior to convening as a group) each participant writes a memory. (In this case the memories were of a positive experience and a negative experience in the last two years relating to my physical appearance on holiday.) The topic acts as trigger to generate memories and later discussion. The memories are written according to a set of rules. Participants are asked to write 1-2 pages on each of the two memories. The writing of the memory has a number of benefits. It provides a discipline for the group, the group remembers more through writing and it gives the everyday experiences of life a status, which is considered of particular importance for women. Participants are asked to write in the third person using a pseudonym, the advantage being that the participant can stand back and view the memory from the outside which helps to avoid justification of the experience. They are also asked to write in as much detail as possible, including even what might be considered to be trivial or inconsequential. By asking for the trivial it is hoped to avoid an evaluation by the participants of what was important or unimportant. Finally, they are asked to describe the experience, rather than interpret the experience, as interpretation smoothes over the rough edges and covers up the absences and inconsistencies.

In Phase 2, the participants convene (in this study, in groups of 4), read and discuss the written memories drawing out their shared social understandings, their collective theorising. Although the women wrote only two memories, the discussion allows for many more memories to emerge as data for study. The discussion is audio-recorded and later transcribed. To lead the 
group into discussion, it is suggested that the group might: look for similarities/commonalities and dissimilarities in the memories; identify clichés and contradictions in the memories; and look for gaps or what is not being written in their memories (but which might be expected to be). In the present study, the women were also asked to consider whether they identified with the memories they were reading, to explain why they felt as they did about their appearance, and to contemplate the importance of physical appearance to the success of a holiday for women in their 20s. As my age prevented me from positioning myself with the young women, I left them to discuss and theorise by themselves, returning at the end to elicit a summary of their discussion and clarification of their meaning. The discussion lasted up to one and three quarter hours and took place at the home of one of the group members. In the final phase of the research, Phase 3, I, as the researcher, collated the material, drawing out the themes across the groups. (Where quotations are used in the following section of the paper, those from the collective discussion are italicised to distinguish them from the individual written memories.)

2.1.2 Study Participants. Four groups of friends aged in their early twenties participated. In each of the groups at least one of the young women was known to the researcher. The researcher approached the women she knew, inviting them to form a group with their friends. The 16 participants (four groups of four) were Australian, white, middle-class and tertiary educated, able-bodied and heterosexual women. Although not asked about their body size, none of them appeared more than an Australian clothes size 12. (Information about body size is included here to assist in the reading of the women's stories.) The study was approved by the University of Technology, Sydney Ethics Committee. To encourage frankness and avoid embarrassment from what might be a sensitive topic, the participants read and discussed the written memories of unknown members of another participant group. Pseudonyms have been used for all participants. The following findings emerged from a homogeneous group of women living in contemporary, Western culture with its specific prescriptions for the body. It is recognised that women from other cultures and times might report different experiences.

2.1.3. Data Analysis. The research questions guided thematic exploration of the written memories and collective understanding of those memories. The data was first analysed by the collective itself in Phase 2, identifying themes from the written memories and collective discussion then summarising in my presence to ensure comprehension. I then continued the thematic analysis identifying themes within and across groups. Analysis of the initial data by a second researcher 
experienced in body image research, and also one of the participants, verified my understanding of the young women's meanings. The trustworthiness of the data was strengthened by these layers of analysis and the employment of a recognised reputable research method. There are, of course, limits to transferability since individuals' experience and knowledge are constructed within a particular social context. However, within that social context, if our lives are produced collectively, then our lived experiences should be subject to universalisation (Haug, 1987).

\subsection{Findings and Discussion}

The holiday was an embodied experience with the women "making and doing the work of bodies - of becoming a body in social space" (Turner, 1996, p. xiii). Although destinations, types of holiday and travel companions varied, there was consensus amongst the women; they could easily understand the written memories of the (other) group they were analysing and identify with their experiences. The memories clearly illustrated an internalisation of cultural standards of the ideal body. Positive memories focussed on feeling thin, toned, appropriately dressed (nice/new clothes), tanned, healthy and fit. There was the expressed perception and feeling among the women, that they felt better about their appearance if they exercised and ate light food. The work involved on holiday in maintaining the body was also recalled by some as an enjoyable experience. Negative memories centred on feeling fat, exposed (in swimmers), ugly, unfit/untoned, bloated, having pale or blotchy skin and inappropriate/unattractive clothes. How much work went into the holiday body practices and whether physical appearance was recalled positively or negatively was related to the women's social understanding of the holiday destination, the type of holiday and who was in the holiday space (family, friends, other tourists, local residents). Their experiences related to their level of social comfort, of fitting in, belonging to a particular sociocultural-physical space which, if abroad, could be a challenge. Their perception of whether or not they approximated the ideal body involved surveillance, comparison with, and feedback from, others.

2.2.1. Surveillance, Social Comparison and Feedback. The women engaged in surveillance and self-surveillance, comparing themselves to other women of their age. When the women perceived their own appearance as better than others, they felt empowered. 
Jane: ... Jane attended the wedding [in Melbourne] and wore her favourite purple dress... with great high heels and felt fantastic. She felt incredibly confident, attractive and sexy. She also felt elegant and classy... As awful as it may sound, Jane was happy to see that she had got her clothing right for the event when so many other women hadn't. She really enjoyed showing off her body and feeling so confident.

Sally: Sally decided it was time for a swim and as she skipped to the water's edge she bumped into an old school friend [Anna]... [Anna's] face seemed more full and her hips more pronounced. Sally seemed tiny by comparison. As the two continued chatting it became apparent just how different they were and just how envious Anna was of what Sally had become. For the first time in years Sally felt a rush of empowerment and surge of pride as Anna quizzed her on her physical fitness routine and diet.

As Coffey (2013) explains, bodies are both affected and affecting. In the above memories, the women's pleasure is likely at the expense of the other women (in Jane's case, other women hadn't got the "clothing right" and, in Sally's memory, Anna was perceived as envious of Sally). Interestingly, when Jane says "As awful as it may sound", she draws attention to a competing gendered discourse (to be supportive of others) which should prevent her from being so pleased with herself. Validation by others that their physical appearance was acceptable (or more than "acceptable") also contributed to the pleasure of the holiday experience.

Sophie: One of her friends, Jennie, commented, and said she looked like a James Bond girl coming out of the water with her blonde hair, big boobs and new bikini! That day made Sophie feel really good about herself.

Sally: As the sun set on yet another perfect day [in Byron Bay] Sally and Pedro made their way to the Beach Hotel... Sally had never felt more beautiful, in her newly purchased frock and towering high heels. Men everywhere seemed drawn to her and the air of elegance she created. Pedro even commented on the power of her prowess and the fact that all eyes were fixed on her. In a town of beach beauties it is often difficult to feel comfortable with oneself, but Sally had never felt more alive. 
The power of others to affect the quality of a holiday experience is apparent in the above written memories and the group discussion below.

F1: ... pretty much it seems [a] positive experience... [is about] your confidence [which] comes from getting compliments.

F4: Why does everyone go to effort to do that stuff? It's so you can look good in front of other people, and so other people can think you look good. [Amy's Group]

The above memories imply the sexualisation of the holiday space (Jordan \& Aitchison, 2008) and the sexual power experienced by the women ("a James Bond girl”; "Men everywhere seemed drawn to her"). The feedback here is from a girlfriend or boyfriend. Although perhaps less likely to comment on sexual prowess, family could enhance an experience with their comments. Feedback was not restricted to those present in the holiday space but also anticipated on return home.

F4: $\quad$ When I was in Samoa, like I did want to tan and stuff so I could come back and make everyone jealous and say I'd been at a tropical place ...

F1: $\quad$ But you feel better... when you've got a tan as well.

F4: ... I do get worried about skin cancer though. And when I was over there, we'd already been there for like over a week and... I've been swimming but I haven't developed a tan, so on like my last day I fully concentrated on tanning. And ... it's bad, like it's really bad. (Kate's Group)

A tanned body is part of the holiday discourse and an expected outcome of a beach holiday. Here the body image discourse that a tan makes "you feel better" is privileged over the health discourse on the dangers of tanning of which the young women were fully aware. 
Compared to the positive memories, the negative memories were less focussed on feedback and more focussed on social comparison. In the negative memories, the women compared themselves less favourably to their travel companions or other women at the destination, viewing themselves as an "outcast" who did not belong to the social group, " the ugly stepsister that had come along for the ride".

Carrie: [In Spain] Carrie felt very uncomfortable in her swimmers. ... Also, she was terribly pale and had skin that had not seen the light of day for months! In contrast, her two friends from Brisbane - Jess and Emma, looked fabulous. They were extremely attractive girls who were blonde, tall, and very thin. Plus, thanks to regular solarium visits in Scotland, they were very tanned and brown. Compared to Carrie who was short, plump and pale!... She was very aware of the contrast between herself and Jess and Emma. Also, all the local Spanish women on the beach were gorgeous too. They looked so comfortable in their very skimpy bikinis... Wherever they went Jess and Emma caught the attention of men. They were constantly being flirted with, given free drinks, discounts at places etc.... She [Carrrie] was often ignored. Even though the three of them were great friends and Jess and Emma didn't treat Carrie any differently from each other, Carrie felt like other people they met treated her differently. Despite having a great relationship with the girls Carrie felt like the ugly 'third wheel' some of the time.

It was the women's perception of themselves in comparison to others which led to the negative appraisal of their appearance. The memories indicated how judgmental the women were of themselves. Carrie's memory above demonstrates the far reaching effects of low body image where self-perception of physical unattractiveness relates to self-perception of social unattractiveness. In a number of the memories, the women were not unhappy with their bodies until other (perceived better-looking) women entered the holiday scene.

Sally: On arrival in Cairns, Sally was feeling happy and excited, despite her skin problems. She was also relatively happy with her body and looking forward to getting a decent tan over the 5 days of sailing. Seeing their friends again was great, except that Sally couldn't help but notice Elizabeth (a year younger than Sally) had lost some weight since their last 
meeting and was looking fantastic, along with a new haircut and flawless skin. Sally was immediately feeling less confident about her body and even more conscious about her skin.

In both the positive and negative memories, the women's thoughts and feelings emerge from their surveillance of other bodies and surveillance of their own (Foucault, 1980). The findings are congruent with what is known in psychology about the interpersonal processes that shape body image. Tantleduff-Dunn and Gokee (2004) outline three primary processes: reflected appraisals (whereby the perceptions of how others appraise us impact on how we evaluate ourselves); feedback on physical appearance; and social comparison. Social comparison theory (Festinger, 1954) asserts that individuals "assess themselves relative to others when other objective criteria are absent" (Forgas, 1992, p. 208). The three types of appraisals encompassed in social comparison theory were evident in the written memories and discussion. The primary type of comparison was Self-evaluation which occurred when the women gathered information regarding their own appearance standing in relation to others. Self-improvement comparisons were evident when the women learned (or thought they learned) how to improve their appearance, for example, by losing weight, and self-enhancement occurred when the women discounted certain information about physical appearance as irrelevant to themself and considered the other person as less endowed on an attribute about which they felt superior (for example, Sally's comparison of her small frame to Anna's “full hips”). Self enhancement allowed the women to protect their self worth and self esteem and maintain positive views about themself (Krayer, Ingeldew \& Ibhofen, 2008).

The findings are supported by previous research with adolescents that body comparison with peers is a stronger mediator of the endorsement of thinness norms and body image concerns than with media models (Carey, Donaghue \& Broderick, 2014). The findings are also supported by previous research which has examined the direction of social comparison (Wheeler \& Miyake, 1992): social comparisons tend to be upward, that is, comparing oneself to someone who is considered to have better physical appearance to oneself (and thus decreasing one's feeling of well-being) rather than downward in which one compares oneself to someone who is considered to have worse physical appearance to oneself (and thus increasing one's feeling of well-being). The closeness of the relationship with a travelling companion often affected whether they were a target for comparison. When holidaying with close friends, physical appearance was considered 
less important. As Krayer et al. (2008) suggest, it might be that close friends are more supportive and protective than other friends. The women were also less concerned about appearance when with family. As Gillen and Lefkowitz state, families are more likely to stress that "what is inside is more important than physical appearance" (2009, p. 184).

2.2.3. Types of Holiday and Body Work. While the type of travel companion could influence one's body image so too could the type of holiday and destination. Different destinations and types of holiday had different meanings as to how one should look in that space and how much work was required to get "that look". Some holidays required less body work (such as not washing one's hair or dressing up) than at home. Nonetheless, surveillance and self-surveillance continued.

Katrina: [Trekking in Vietnam] They didn't worry about what they were wearing or how they looked because everyone there was dressed for walking and warmth...

Camping and trekking required less work than being in a fashionable city like New York where appearance was considered important regardless of with whom one was travelling. It was all about fitting in with others in that context.

Shelagh: It was not a posh or touristy beach; no one was in the most trendy swimmers or posing in any way; everyone seemed to be having a good time not worrying about what they looked like. This made Shelagh feel she could walk around the beach in her bikini and not worry about her chunky legs, she felt happy with her whole body and did not feel the need to put on a pair of shorts or cover up, as she normally does on Sydney beaches. She felt relaxed and happy with herself, free to enjoy the moment and not feel judged about her body.

Memories, such as those above, were rare; for most holidays, the body ideal was prominent as were preparation and maintenance to sustain it. Preparations for the holiday included the purchase of new clothes, spray tans, waxed bodies, painted nails, haircuts and exercise. Work was required on holidays to maintain this image but sometimes time and space prevented. 
Sarah: [boating holiday with her boyfriend and his family] She felt very bad about her physical appearance as she did not have enough time or enough room to put on her make up or to do her hair. Sarah was used to being able to have a shower whenever she liked, and having her own personal space.

Shared space (in this case, under the gaze of boyfriend and family) was problematic. However, for others, the holiday offered a communal space that turned body practices from work into play. Whether this is considered problematic, evidencing interiorisation of the discourse, or whether it is seen as empowering resistance to the discourse is questionable.

Carrie: They turned on some music in their motel room while they got ready and had a couple of drinks. After a big shopping spree in New York they had lots of new clothes to choose from. The girls all tried on different outfit combinations and helped each other decide what to wear. Carrie washed, blow-dried and straightened her hair, and properly put on make-up... Carrie really enjoyed putting some effort into the way she looked and it was so fun doing it with the other girls.

Another woman recalled positively:

Louise: It was bedlam back in the girls room, fake tan being sprayed from one end of the room to the other, wax strips stuck in the carpet... and a scream coming from the bathroom because someone's hair had become caught in a hair dryer....

The holiday discourse for a carefree, relaxed experience is often associated with a beach/pool holiday with "the bikini" essential holiday clothing for that space. While there were some women who recalled feeling positive about their physical appearance at the beach/pool, for most, the site was the focus of their negative holiday experiences.

Jane: Jane doesn't really enjoy beach holidays. There is way too much to worry about! Being fit and slim and looking nice in a bikini (doesn't happen to any woman), not getting 
sunburned, making sure your legs are shaved/waxed etc., making sure you are wearing a bikini that doesn't ride up, wash off etc.

The group discussing Jane's memory identified with her thoughts and feelings.

F3: $\quad$ Yeah. Men don't even have to shave.

F4: $\quad$ They can just wear board shorts.

F2: $\quad$ Yeah, I reckon this girl's similar ideas to us.

F4: $\quad$ Yeah

F1: $\quad$ I hated that. ... when I was in Italy and you just did the beach all the time, and like having to worry about 'oh I have to shave again, I have to shave down'.

F4: $\quad$ Nothing to hide behind. [Amy's group]

Negative appraisal of appearance was most keenly recalled when the women's normally concealed bodies were publicly on view. The women spoke of feeling "fat", "naked”, "exposed", "on display" and "judged".

Yvette: Although the trip was going brilliantly, her fear of stepping into her swimwear to go swimming in the pool or at the beach was preventing her from really having a good time as she constantly felt insecure. One particular memory was while swimming in the pool at the resort. She felt as though everyone around her was staring at her while entering and exiting the swimming pool. She would walk to the stairs of the pool and walk down each stair slowly to ensure her body didn't move too much during the process.

The group discussing Yvette's memory related her conscious body posing to similar advice given in women's magazines on how best to present oneself. However, they agreed: “When Yvette doesn't want to walk down a set of stairs 'cause she's worried about jiggling, society is not giving her the right message" [F3 in Jane's Group]. 
As with other examples above, Yvette's memory implies objectified body consciousness, observing herself as she imagines others are seeing and judging her. Tiggemann \& Andrew (2012a) found that when comparing the (imagined) wearing of revealing clothing like bathers with more modest clothing such as a sweater and jeans, bathers lead to a greater state of surveillance or objectified body consciousness. In the present study, some of the painful bather recollections involved others' expectation that the women perform in their bikinis (e.g. by dancing on a tabletop or modelling a sarong).

Amy: The boat crew then informed everyone that they would be demonstrating how to tie sarongs and Amy felt suddenly sick from nervousness when she realised that she would have to be one of the models.

To avoid exposure, the women recalled their concealing strategies. Yvette, above, focused on her body movements as she entered the water and lay by the pool. Another reported wearing "big, baggy clothes to hide her figure, and sunglasses to hide her face". Some made pledges to lose weight when they returned home to avoid future embarrassment (beliefs about appearance control). Despite the women in the study being of an age and body size which in Western culture most closely approximated the ideal, it was apparent that many of the women were prevented from fully enjoying a common holiday activity - swimming - through self-consciousness of their scantily-clad bodies.

F2: $\quad$... I feel intimidated going to the beach

F3: Yeah, yeah.

F2: $\quad$ Like clearly there's something wrong if somebody

F3: $\quad$ Yeah, that's true.

F2: $\quad$... if girls like us, none of us are overweight, we've all great bodies

F4: $\quad$ Anyway it's like walking around in your underwear.

F1: $\quad$ Yeah, it basically ...

F3: $\quad$ You know ...(Laughter) sometimes... they're skimpier than your underwear.[Jane's Group] 
The emotions expressed by many of the women at the beach/pool suggest not all are comfortable in what can be considered a sexualised space. The women's feelings and employed strategies to negotiate constraints were similar to those of adolescent Australian girls at public swimming pools described by James (2000). If the message of women's lifestyle magazines is that women should not be happy to be unclothed in public spaces unless they have the prescribed body (Jordan, 2007), then one could say that, for many women, the magazines have succeeded in their communication.

The women were the bearers of the discourse, comparing themselves to others and interiorising others' gaze. For the most part the interiorised gaze was not confined to the male gaze (highlighted by Jordan and Aitchison, 2008) but included a female gaze. These findings are in contrast to those of Berdychevsky, Gibson and Bell (2013) who found that, for women of various ages, all-female girlfriend getaways created a space for existential authenticity, an opportunity to be oneself, "not having to pay attention to their make-up and clothing as they were free from the male gaze" (p. 619). An explanation for the difference in findings might lie with cultural and age characteristics of the participants or the closeness of the friendships. The present findings align more closely with Davison's proposal: "females may be evaluating their bodies in relation to the thin ideal they believe is held by their female peers" $(2012$, p. 245). The women's explanation for the female body ideal did not cite gendered power relations but rather society and the media (supporting conclusions of Murnen \& Seabrook, 2012). While the women believed that the body ideal was more prescriptive for women than men, they also considered young men to be subjected to a limiting body discourse. Their interpretation of the female body discourse has more of a consumerist, than feminist, focus perhaps mirroring the rise of the consumerist society and the decline in young women's subscription to a feminism born of gender inequality.

2.2.4. Salience of Appearance to Holiday Enjoyment. The association between achievement of the body ideal and holiday enjoyment was insignificant or marginal for some but salient for most. High satisfaction with her appearance led Sarah to proclaim: "[she] felt like she had never looked better and was enjoying her holiday even more because of it". On the other hand, for Katrina, "The enjoyment of the holiday decreased as she forgot about this new and exciting country (Vietnam) and worried about her appearance" and for Louise, a bad haircut "seriously affected" her European holiday. These memories of the body remain with the women. As Jane said “... $a$ body is really important to holidays because you really remember how you were feeling about 
your body". Fredrickson and Roberts explain that body monitoring "might best be viewed as a strategy many women develop to help determine how other people will treat them, which has clear implications for their quality of life" (1997, p. 180). For many women, physical appearance can be taken as currency of their worth, as reflected in the memories below.

Sarah: She wanted to impress them (boyfriend's family) and thought that by looking nice, they would think she was a very nice person and that their son was very lucky to have her.

Sophie: By speaking no Italian (language of her companions), looks was all she had to these people, and she felt like they weren't good enough.

Fredrickson and Roberts note that some women are plagued by others' perspectives in most social contexts, while other women experience self-objectification only in certain contexts.

Throughout the course of a day, women enter into and exit from multiple contexts, some that protect them from the negative repercussions of objectification, and some that do not. To the extent that particular social contexts accentuate women's awareness of actual or potential observers' perspectives on their bodies, certain types of experiences are likely to ensue. (1997, p. 180)

Leisure and tourism contexts are often conceived as heterotopia (Foucault, 1984), sites of empowerment where one can transgress gendered prescriptions. The present study demonstrated that a holiday-in-general was not such a site confirming that "everyday life and tourism are not separate realms of practice" (Hannam \& Knox 2010, p. 103). Indeed the women often said as much. Evident in the women's accounts was the "reproduction of social habits" (Crouch and Desforges, 2004, p.10) of surveillance, objectification and social comparison resulting in discomfort and lowered self-worth. Although not constrained from participating in tourist activities, the women were often constrained from full enjoyment, reducing opportunities for peak motivational experiences/flow. Foucault's "normalized" and "docile", "disciplined bodies" were evident in many of the accounts. Even the memories of "empowerment" were not the outcome of resistance to the dominant discourse but rather achievement of it. Enjoyment in 
communal body work was also reinforcing. As Wood-Barcalow, Tylka \& Augustus-Horvath stress, positive body image "is not merely the absence of negative body image" (2010, p. 106). The situation can be seen as "precarious" when positive sense of self is reliant on the hegemonic body ideal (Coffey, 2012, p. 13). While these body practices might make the women feel good, the "affects" are limited with other possibilities for experiencing the body "not immediately available" (Coffey, 2012, p. 13). In many ways, the holiday can be conceived as a site where resistance is more difficult than in everyday. As a distinctive event, holidays can take on a certain importance. They are socially constructed with the promise of perfection/“the ideal", which could also incorporate the body ideal (one woman confessed that she always imagined she would be thinner on holidays and packed her "thin" clothes that she wouldn't wear at home). As one group said, "You want to make the most of it [a holiday] and feeling good [about your physical appearance] is a part of that". Many holiday spaces/places are sexualised and gendered (Jordan \& Aitchison 2008) making resistance particularly difficult.

Nonetheless, there were some types of holiday or spaces within the holiday that in various degrees allowed the women to escape the body discourse; few were plagued by a restrictive body discourse for the whole holiday. Although the women were still aware of fitting in with the appearance norms of the group, trekking and camping holidays (where the rules are lessened and bodily exposure not required) could afford the women some peace as could the company of family or close friends. Moving through different social situations (of people and places) with different body discourses allowed for the possibility, as Crouch and Desforges, said, "of making something different from only pre-figured and mundane protocols" (2004, p.10). While places are already socially constructed, it is at the point of visitation through our embodied experiences, that we construct and consume places (Rakić \& Chambers 2012). Here it is possible to see the body as "becoming", a "process" rather than a project (Coffey, 2013). This is a hopeful outcome for tourism. The extent to which women can transgress gendered appearance prescriptions in hegemonic holiday spaces/places is uncertain, but a holiday is a social situation where choice is possible. One can choose to take a camping holiday, visit that "family" beach or travel with those with whom one feels comfortable. At the same time, tourism is a temporary condition where risks could be taken.

\section{CONCLUSION}


The present study explores how young Australian women of particular subjectivities experience tourism through their bodies and their bodies through tourism. In so doing, it goes beyond a representational approach to tourism and physical appearance to examine young women's lived experience of their appearance on holiday. The written memories and discussion illustrate how the body is shaped by and shapes social relations, how the body is in the process of becoming, affected and affecting. Foucault's conceptualisation of surveillance and self-surveillance in the normalisation of bodies and the psychological theories of objectification (Fredrickson \& Roberts, 1997 ) and social comparison (Festinger, 1954; Wheeler \& Miyake, 1992) are useful in understanding how women come to perceive their bodies as they do in the holiday space. The women accepted their own and others' holiday memories as normal for a woman in the modern, Western world, they identified with the pursuit of the body ideal but, at the same time, they were not unaware of the risks associated with the discourse. Yet, it was rare for the women to question this discourse and when they did, it was seen as a media issue rather than a feminist issue born out of a patriarchal culture.

That the women had generally absorbed the hegemonic body ideal was apparent in their memories and discussion. It was clear that this ideal could cause shame, embarrassment and discomfort when women felt they did not approximate this ideal and pleasure when they felt they had. Problematically, pleasure and rewards from fulfilling these prescriptions can be positively reinforcing thus sustaining the ideology of beauty. In both cases, perceptions and feelings relate to surveillance, comparison, or feedback from others. The women's experience of their physical appearance was, in various degrees, salient to the holiday experience. An understanding of their experiences recognises the socially constructed meaning of the holiday and different spaces/places within the holiday. This includes the other people who inhabit that space/place. The holiday in general cannot be assumed to be a heterotopia. While some types of holiday (such as camping/trekking and "family" beach) and some types of travel companion (family and close friends) can take the pressure off body work practices, many reinforce the sexualised, gendered body work. One can conclude that ideal feminised identity was more likely to be reinforced than resisted on holiday. Sometimes, physical appearance could be of greater importance on holiday than at home.

Memory-work, entailing the writing of memories and the collective discussion was well suited to the topic. In the familiar company of friends at home, amiable discussion concerning a 
not-unfamiliar topic ensued. The collective essence of Memory-work allowed the women to make sense of their shared experiences and, one hopes, confront and question the constraining discourse. It could be argued that the significance of appearance in the women's overall holiday experience is uncertain since participants were alerted to/required to address this particular topic. Nonetheless, the emotions stirred by the memories demonstrated that physical appearance was not an irrelevant consideration in the holiday experience. Allowing the owner of the memories to remain anonymous is likely to have contributed to the women's frankness of a potentially sensitive topic. In neither the written memories nor the discussion was there evidence that the women were withholding their ideas and feelings. However, the tendency not to voice downward comparisons might have been due to an unwillingness to appear arrogant amongst other women (a social prescription) especially in Western society where "fat talk" is prolific (Salk \& EngelnMaddox, 2011).

Young women have been the focus of the present study (and much of the body image research), however, the evidence that other-aged women (Liechty, Freeman \& Zabriskie, 2006; McKinley, 2006) also experience body dissatisfaction suggests that future tourism research should also explore their experiences. The women in this study were middleclass, educated, heterosexual, able-bodied, Australian women; the inclusion of other social groups of women would widen our knowledge of body image and appearance experiences. How familiar the study participants were with feminist discourse is uncertain. Further research could explore women's understanding of the politics of the body ideal. The consistent finding in the literature, that body image is increasingly important to men, also calls for the study of their appearance experiences on holiday.

Holidays, constructed as a time of escape and liberation, are considered beneficial for one's physical and mental wellbeing. However, a holiday does not occur in a vacuum, it is not a neutral space as evidenced in this study. Most women brought with them their idealised standards of the body and their body practice of self-surveillance thus reducing opportunities for peak motivational experiences. The issue of body image and physical appearance goes beyond tourism, requiring broad ranging cultural change in current Western neo-liberal societies. In the meantime, the tourism industry has a social obligation to support the health professions and governments in their endeavours to promote positive body images and comfortable spaces for women thus encouraging an expanded sense of self and power (Yarnal et al., 2006). This is 
especially important for tourism since the holiday is constructed as a space of escape, freedom, recreation and wellbeing. Seeing bodies not as a static given but rather as "becoming" with the focus on "what a body can do" (Coffey 2013, p. 6) provides possibilities for change. As Coffey says, if one moves beyond the body ideal to affirm bodily differences and positive styles of life, the greater the body's force, "the more it can do" (2012, p. 14).

\section{REFERENCES}

Abramovici, M. (2007). The sensual embodiment of Italian women. In A. Pritchard, I. Ateljevic, N. Morgan \& C. Harris (Eds.), Tourism and gender: Embodiment, sensuality and experience (pp.107-125). Wallingford, Oxon: CABI Publishing.

Berdychevsky, L., Gibson, H. \& Bell, H. (2013). Girlfriend getaways and women's well-being. Journal of Leisure Research, 45, 602-623.

Berdychevsky, L., Gibson, H. \& Poria, Y. (2014). Inversions of sexual roles in women's tourist experiences: Mind, body, and language in sexual behaviour. Leisure Studies, DOI:

10.1080/02614367.2014.938770

Bordo, S. (1989). The body and the reproduction of femininity: A feminist appropriation of Foucault.In A. Jaggar \& S. Bordo (Eds.), Gender/body/knowledge: Feminist reconstructions of being and knowing (pp.13-33). New Brunswick, NJ: Rutgers University Press.

Carey, R., Donaghue, N. \& Broderick, P. (2014). Body image concern among Australian adolescent girls: The role of body comparisons with models and peers. Body Image, 11, 8184.

Clay, D., Vignoles, V. \& Dittmar, H. (2005). Body image and self-esteem among adolescent girls: Testing the influence of sociocultural factors. Journal of Research on Adolescence, 15(4), 451-477.

Coffey, J. (2012). Bodies, health and gender: Exploring body work practices with Deleuze.

Melbourne: Youth Research Centre, Melbourne Graduate School of Education, The University of Melbourne

Coffey, J. (2013). Bodies, body work and gender: Exploring a Deleuzian approach. Journal of Gender Studies, 22(1), 3-16. 
Crawford, J., Kippax, S., Onyx, J., Gault, U. \& Benton, P. (1992). Emotion and gender:

Constructing meaning from memory. London: Sage.

Crouch, D. (2000). Places around us: Embodied lay geographies in leisure and tourism. Leisure Studies, 19, 63-76.

Crouch, D. \& Desforges, L. (2004) The sensuous in the tourist encounter: Introduction to the power of the body in Tourist Studies. Tourist Studies 3(1), 5-22.

Davidson, P. (1996). Women's leisure: The woman's perspective of holidays, Unpublished Masters Thesis, Melbourne Institute of Technology, Australia.

Davison, T. (2012). Body image in social contexts. In T. Cash (Ed.), Encyclopedia of body image and human appearance (pp. 243-249). London; Elsevier.

Felski, R. (2006). "Because it is beautiful": New feminist perspectives on beauty. Feminist Theory, 7(2), 273-282.

Festinger, L. (1954). A theory of social comparison processes. Human Relations, 7, 117-140.

Forgas, J. (1992). Interpersonal behaviour: The psychology of social interaction. Sydney: Maxwell Macmillan.

Foucault. M. (1980). The eye of power. In C. Gordon (Ed.), Power/Knowledge: Selected Interviews and Other Writings 1972-1977 Michel Foucault, trans. C. Gordon, L. Marshall, J. Mepham, \& K. Soper, (pp.146-165), New York: Pantheon Books.

Foucault, M. (1984). Of other spaces, heterotopias. Architecture, Mouvement, Continuité 5, 4649.

Frederick, J. \& Shaw, S. (1995). Body image as a leisure constraint: Examining the experience of aerobic exercise classes for young women. Leisure Sciences, 17, 57-73

Fredrickson, B. \& Roberts, T. (1997). Objectification theory: Toward understanding women's lived experiences and mental health risks. Psychology of Women Quarterly, 21, 173-206.

Gillen, M. \& Lefkowitz, E. (2009). Emerging adults' perceptions of messages about physical appearance. Body Image, 6, 178-185.

Hannam, K. \& Knox, D. (2010). Understanding tourism: A critical introduction. London: Sage.

Haug, F. (1987). Female sexualization: A collective work of memory. Trans. E. Carter, London: Verso.

James, K. (2000). "You can feel them looking at you": The experiences of adolescent girls at swimming pools. Journal of Leisure Research, 32(2), 262-280. 
Jeffreys, S. (2005). Beauty and misogyny: Harmful cultural practices in the west. London: Routledge.

Jordan, F. (1998). “Shirley Valentine: Where are you?” In C. Aitchison \& F, Jordan (Eds.), Gender, space and identity: Leisure culture and commerce (pp.69-87). Eastbourne: Leisure Studies Association.

Jordan F. (2007). Life's a beach and then we diet: Discourses of tourism and the 'beach body' in UK women's lifestyle magazines. In A. Pritchard, I. Ateljevic, N. Morgan \& C. Harris (Eds.), Tourism and gender: Embodiment, sensuality and experience (pp. 92-106). Wallingford, Oxon: CABI Publishing.

Jordan, F. \& Aitchison, C. (2008). Tourism and the sexualisation of the gaze. Solo female tourists' experiences of gendered power, surveillance and embodiment. Leisure Studies, 27(3), 329349.

Krayer, A., Ingledew, D. \& Iphofen, R. (2008). Social comparison and body image in adolescence: A grounded theory approach. Health Education Research, 23, 892-903.

Liechty,T., Freeman, P. \& Zabriskie, R. (2006). Body image and beliefs about appearance: Constraints on the leisure of college-age and middle-age women. Leisure Sciences 28, 311330.

McKinley, N. (2004). Feminist perspectives and objectified body consciousness. In T. Cash \& T. Pruzinsky (Eds.), Body image: A handbook of theory, research, and clinical practice (pp. 5562). New York: The Guilford Press.

McKinley, N. (2006). The developmental and cultural contexts of objectified body consciousness: A longitudinal analysis of two cohorts of women. Developmental Psychology, 42, 679-687.

McKinley, N. \& Hyde, J. (1996). The Objectified Body Conscious Scale. Psychology of Women Quarterly, 20, 181-215.

Mission Australia (2013). Youth survey 2013. Sydney: Mission Australia.

Murnen, S. \& Seabrook, R. (2012). Feminist perspectives on body image and physical appearance. In T. Cash (Ed.), Encyclopedia of body image and human appearance (pp. 438443). London: Elsevier.

Neighbors, L. \& Sobal, J. (2008). Weight and weddings: Women's weight ideals and weight management behaviors for their wedding day. Appetite, 50, 550-554. 
Obrador- Pons, P. (2003). Being on holiday: Tourist dwelling, bodies and place. Tourist Studies, 3, 47-66.

Olivardia, R. (2002). Body image and muscularity. In T.F. Cash \& T. Pruzinsky (Eds.), Body image: A handbook of research, theory and clinical practice (pp. 210-218). New York: The Guilford Press.

Pinhas, L., Toner, B., Ali, A., Garfinkel, P. \& Stuckless, N. (1999). The effects of the ideal of female beauty on mood and body satisfaction. International Journal of Eating Disorders, 25(2), 223-226.

Polivy, J. \& Herman, C. P. (2002). Causes of eating disorders. Annual Review of Psychology, 53(1): 187-213.

Prichard, I. \& Tiggemann, M. (2011). Appearance investment in Australian brides-to-be. Body Image, 8, 282- 286.

Pritchard, A. (2001). Tourism and representation: A scale for measuring gendered portrayals. Leisure Studies, 20(2): 79-94.

Pritchard, A., Morgan, N., Ateljevic, I. \& Harris, C. (2007). Tourism and gender: embodiment, sensuality and experience. Wallingford: CAB International.

Rakić, T. \& Chambers, D. (2012). Rethinking the consumption of places. Annals of Tourism Research, 39(3), 1612-1633.

Richards, G. (2002). Gastronomy: An essential ingredient in tourism production and consumption? In A. Hjalager \& G. Richards (Eds.), Tourism and gastronomy (pp. 3-20). London: Routledge.

Rodin, J., Silberstein, L. \& Striegel-Moore, R., (1984). Women and weight: A normative discontent. Nebraska Symposium on Motivation, 32, 267-307.

Salk, R. \& Engeln-Maddox, R. (2011). If you're fat, then I'm humungous!: Frequency, content and impact of fat talk among college women. Psychology of Women Quarterly, 35, 18-28.

Shilling, C. (2003). The body and social theory. London: Sage.

Small, J. (2004). Memory-work. In J. Phillimore \& L. Goodson (Eds.), Qualitative research in tourism: Ontologies, epistemologies and methodologies (pp. 255-272). London: Routledge.

Small, J. (2005). Women's and girls' holiday experiences over the life-course, Unpublished doctoral dissertation, University of Technology, Sydney, Australia. 
Small, J. (2007). The emergemce of the body in the holiday accounts of women and girls. In A. Pritchard, N. Morgan, I. Ateljevic \& C. Harris (Eds). Tourism and gender: Embodiment, sensuality and experience (pp. 73-91). Wallingford, Oxon: CABI Publishing.

Small, J., Harris, C. \& Wilson, E. (2008). A critical discourse analysis of in-flight magazine advertisements: The "social sorting" of airline travellers? Journal of Tourism and Cultural Change, 6(1), 17-38.

Swain, M. (2004). (Dis)embodied experience and power dynamics in tourism research In J.

Phillimore \& L. Goodson (Eds.), Qualitative research in tourism: Ontologies, epistemologies and methodologies (pp. 102-118). London: Routledge.

Tan, A. (2005). Saving fish from drowning. London: Harper.

Tantleduff-Dunn, S. \& Gokee, J. (2004). Interpersonal influences on body image development. In T. Cash \& T. Pruzinsky (Eds.), Body image: A handbook of theory, research, and clinical practice (pp. 108-116). New York: The Guilford Press.

Tiggemann, M. \& Andrew, R. (2012a). Clothes make a difference: The role of selfobjectification. Sex Roles, 66, 646-654.

Turner, B. (1996). The body and society: Explorations in social theory, $2^{\text {nd }}$ edn. London: Sage. Veijola, S. \& Jokinen, E. (1994). The body in tourism. Theory, culture and society, 11, 125-151. Wearing, B. (1990). Beyond the ideology of motherhood: Leisure as resistance. Australia New Zealand Journal of Sociology, 26(1), 36-58.

Wearing, B. (1998). Leisure and feminist theory. Thousand Oaks, CA: Sage.

Wheeler, L. \& Miyake, K. (1992). Social comparison in everyday life. Journal of Personality and Social Psychology, 62, 760-773.

Wood-Barcalow, N., Tylka, T. \& Augustus-Horvath, C. (2010). “But I like my body”: Positive body image characteristics and a holistic model for young-adult women. Body Image, 7, 106-116.

Yarnal, C., Hutchison, S. \& Chow, H. (2006). "I could probably run a marathon right now": Embodiment, space, and young women's leisure experience. Leisure Sciences, 28, 133-16. 